\title{
Ammonia-Borane Dehydrogenation Promoted by an Osmium Dihydride Complex: Kinetics and Mechanism
}

\author{
Miguel A. Esteruelas, * Ana M. López, Malka Mora, and Enrique Oñate \\ Departamento de Química Inorgánica, Instituto de Síntesis Química y Catálisis Homogénea (ISQCH), Centro de Innovación \\ en Química Avanzada (ORFEO-CINQA), Universidad de Zaragoza-CSIC, 50009 Zaragoza, Spain
}

\begin{abstract}
Complex $\mathrm{OsH}_{2}(\mathrm{CO})\left(\mathrm{P}^{\mathrm{i}} \mathrm{Pr}_{3}\right)_{2}$, generated from $\mathrm{OsH}_{2}(\mathrm{CO})\left(\eta^{2}-\mathrm{CH}_{2}=\mathrm{CHEt}\right)\left(\mathrm{P}^{\mathrm{i}} \mathrm{Pr}_{3}\right)_{2}$ by dissociation of the olefin, promotes the release of 1 equiv of $\mathrm{H}_{2}$ from ammonia-borane and the formation of polyaminoborane. The dehydrogenation rate law is of the form $d\left[\mathrm{H}_{2}\right] / d t=k[\mathrm{Os}]$ with activation parameters of $\Delta H^{*}=19.6 \pm 2.5 \mathrm{kcal} \cdot \mathrm{mol}^{-1}$ and $\Delta S^{*}=6 \pm 9 \mathrm{cal} \cdot \mathrm{mol}^{-1} \cdot \mathrm{K}^{-1}$. On the basis of kinetic results, spectroscopic NMR observations, and DFT calculations, the dihydride-dihydrogen derivative $\mathrm{OsH}_{2}\left(\eta^{2}-\right.$ $\left.\mathrm{H}_{2}\right)(\mathrm{CO})\left(\mathrm{P}^{\mathrm{i}} \mathrm{Pr}_{3}\right)_{2}$ is proposed as key intermediate for the dehydrogenation. Its formation involves the concerted $\mathrm{BH}-$ and $\mathrm{NH}-$ hydrogen transfers from the amine-borane to the metal center and to a hydride ligand, respectively.
\end{abstract}

KEYWORDS: ammonia-borane dehydrogenation, osmium, dihydride, dihydrogen, kinetic, DFT, mechanism

Hydrogen has an energy content per mass that is about three times that of the carbon-based fossil fuels. Furthermore, its oxidation with $\mathrm{O}_{2}$ gives water instead of the undesirable greenhouse gas $\mathrm{CO}_{2}$. However, unfortunately, the energy content per volume is very low at standard temperature and pressure. The concept of chemical storage is a particularly attractive strategy to adjust the storage size. ${ }^{1}$ In this context, ammonia-borane is a promising material due to its high hydrogen content and the fact that a variety of transition metal compounds, ${ }^{2}$ including carbonyl derivatives of group $6,{ }^{3}$ and $\mathrm{Fe},{ }^{4} \mathrm{Ru},{ }^{5} \mathrm{Rh},{ }^{6} \mathrm{Ir}^{7} \mathrm{Ni}^{8}$ and $\mathrm{Pd}^{9}$ species, have the ability of promoting its kinetically controlled dehydrogenation. ${ }^{10}$

Two general mechanisms are being considered in order to rationalize the dehydrogenation process (Scheme 1), on the basis of computational studies and a few experimental observations: ${ }^{11}$ inner-sphere (a) and outer-sphere (b). The first of them is characterized by a cyclic change of two units in the metal center oxidation state of the involved species. The concerted or stepwise $\mathrm{BH}$ and $\mathrm{NH}$ hydrogen transfers from ammonia-borane to the catalyst metal center give aminoborane and generate a dihydride intermediate, which subsequently undergoes an intramolecular reduction to form a dihydrogen intermediate. The release of the coordinate $\mathrm{H}_{2}$ molecule from the latter affords the catalyst again. In contrast to the innersphere process, the oxidation state of the catalyst metal center does not change during the outer-sphere catalysis and the dihydrogen formation is ligand assisted. Such a mechanism requires the catalyst to possess a group in the coordination sphere of the metal center with sufficiently basic free electron pairs (X). Thus, because the substrate contains hydridic $\mathrm{BH}$ and protic NH bonds, the simultaneous or nearly simultaneous $\mathrm{BH}$ hydride transfer to the metal center and $\mathrm{NH}$ proton transfer to the coordinated ligand $\mathrm{X}$ are possible. The subsequent $\mathrm{H}^{+}$ transfer from the $\mathrm{XH}$ group to the hydride ligand in the resulting species yields the key dihydrogen intermediate. A third mechanism is observed when the catalyst contains a hydride ligand (c, in Scheme 1); the direct $\mathrm{NH}$ transfer to the latter affords the dihydrogen intermediate without any change in the metal oxidation state nor ligand assistance. ${ }^{12}$

Scheme 1. Mechanistic Proposals for the Catalytic Ammonia-Borane Dehydrogenation

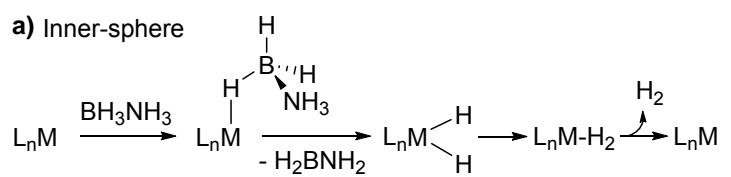

b) Outer-sphere $\quad \mathrm{H}$

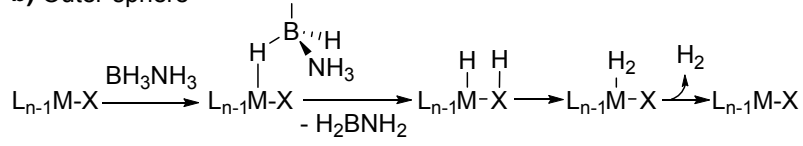

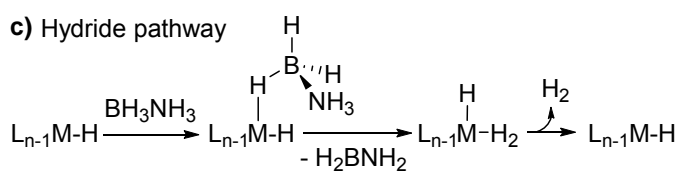

We have recently shown that osmium should be included among the relevant metals in amine-borane dehydrocoupling. ${ }^{13}$ Now, we report an osmium promoted ammonia-borane dehydrogenation via a $\mathbf{c}$ type mechanism, on the basis of a kinetic investigation and DFT calculations.

The known five-coordinate complex $\mathrm{OsHCl}(\mathrm{CO})\left(\mathrm{P}^{\mathrm{i}} \mathrm{Pr}_{3}\right)_{2}{ }^{14}$ reacts with ${ }^{\mathrm{n}} \mathrm{BuLi}$ to give the dihydride-1-butene derivative $\mathrm{OsH}_{2}(\mathrm{CO})\left(\eta^{2}-\mathrm{CH}_{2}=\mathrm{CHEt}\right)\left(\mathrm{P}^{\mathrm{i}} \mathrm{Pr}_{3}\right)_{2}$ (1), as a result of the replacement of the chloride ligand of the starting compound by a butyl group and a subsequent $\beta$-hydrogen elimination reaction at the latter. ${ }^{15}$ In tetrahydrofuran, complex 1 dissociates the coordinated olefin and the resulting dihydride $\mathrm{OsH}_{2}(\mathrm{CO})\left(\mathrm{P}^{\mathrm{i}} \mathrm{Pr}_{3}\right)_{2}$ (2) promotes the release of 1 equiv of molecular hydrogen from ammonia-borane, with a turnover frequency value at $50 \%$ conversion $\left(\mathrm{TOF}_{50 \%}\right)$ of $46 \mathrm{~h}^{-1}$, at $31{ }^{\circ} \mathrm{C}$ and constant atmospheric pressure. Figure 1 shows the course of the dehydrogenation (eq 1), which yields polyaminoborane, 
according to the IR of the formed white insoluble material ${ }^{16}$ (Figure S1).

$$
\mathrm{nBH}_{3} \mathrm{NH}_{3} \stackrel{1}{\longrightarrow} \mathrm{nH}_{2} \uparrow+\left[\mathrm{BH}_{2} \mathrm{NH}_{2}\right]_{\mathrm{n}} \downarrow
$$

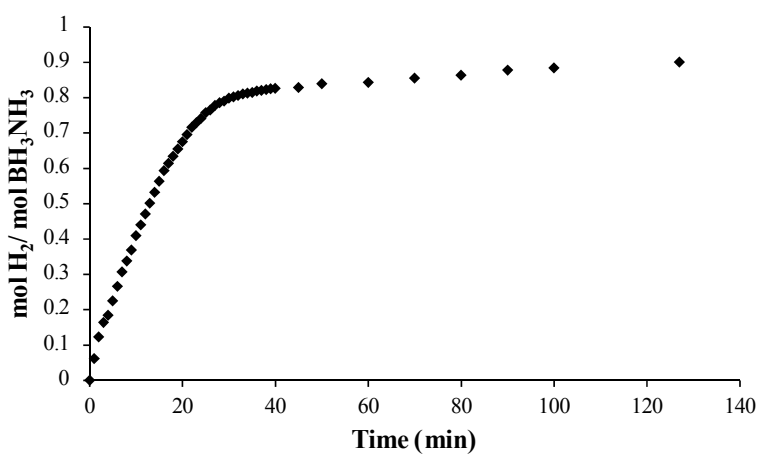

Figure 1. $\mathrm{H}_{2}$ gas evolution in the catalytic dehydrogenation of $\mathrm{BH}_{3} \mathrm{NH}_{3}(0.33 \mathrm{M})$ with $1\left(1.67 \cdot 10^{-2} \mathrm{M}\right)$ in THF at $304 \mathrm{~K}$.

The amount of $\mathrm{H}_{2}$ formed was measured by displacing vaseline oil from a gas buret (Figure S2). In an effort to shed light into the mechanism of the dehydrogenation, the kinetic of the process was studied. Initial rates were determined from the gas evolution experiments (Figure 2) by using eq 2, where $d V / d t$ is the initial rate measured from the gas evolution experiments corrected to $1 \mathrm{~atm}, \mathrm{R}$ is the molar gas constant, $T$ is the temperature $(\mathrm{K})$ and $V_{\text {sol }}$ is the total volume of the reaction solution.

$$
d\left[\mathrm{H}_{2}\right] / d t=(d V / \mathrm{d} t) / R T V_{\text {sol }}
$$

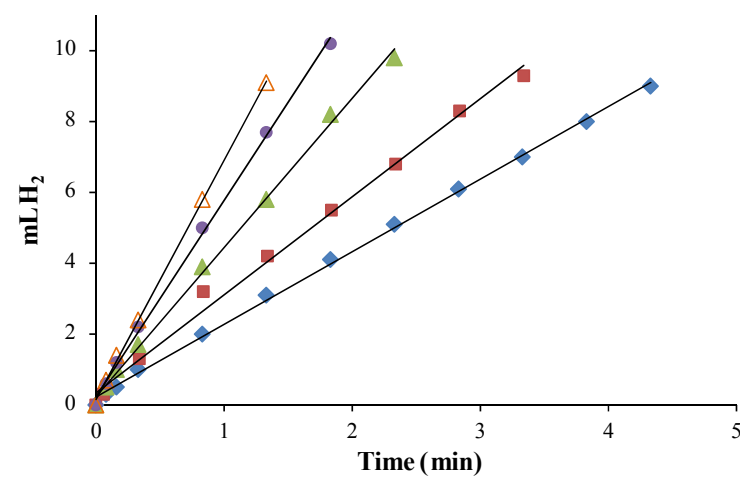

Figure 2. Plots of $\mathrm{H}_{2}$ evolved for the catalytic dehydrogenation of $\mathrm{BH}_{3} \mathrm{NH}_{3}(0.33 \mathrm{M})$ at different [1] in THF at $304 \mathrm{~K}$. [1]: $0.0133 \mathrm{M}$ $(\diamond), 0.0167 \mathrm{M}(\bullet), 0.025 \mathrm{M}(\Delta), 0.033 \mathrm{M}(\bullet), 0.042 \mathrm{M}(\Delta)$.

A simple rate law for the dehydrogenation of ammoniaborane catalyzed by $\mathbf{1}$ is:

$$
d\left[\mathrm{H}_{2}\right] / d \mathrm{t}=k\left[\mathrm{BH}_{3} \mathrm{NH}_{3}\right]^{a}[\mathbf{1}]^{b}
$$

The rate dependence on ammonia-borane concentration was determined by measuring the initial rates with variable $\left[\mathrm{BH}_{3} \mathrm{NH}_{3}\right]_{0}$ from 0.17 to $0.5 \mathrm{M}$ but a fixed concentration of osmium precursor of $1.67 \cdot 10^{-2} \mathrm{M}$ (Table 1 ). Under these conditions the value for the rate is constant within the experimental errors (Figure S3), indicating that the dehydrogenation has no dependence on the concentration of ammonia-borane, i. e., $a=0$ in eq 3. Similarity, to determine the reaction order for the osmium precursor, initial rates were measured by varying the precursor loading from $1.33 \cdot 10^{-2}$ to $4.20 \cdot 10^{-2} \mathrm{M}$ with fixed
$\left[\mathrm{BH}_{3} \mathrm{NH}_{3}\right]_{0}$ of $0.33 \mathrm{M}$. The plot of $\ln \left(d\left[\mathrm{H}_{2}\right] / d t\right)$ versus $\ln [\mathbf{1}]$ yields a straight line of slope $1.03 \pm 0.04$ (Figure S4), demonstrating that the reaction is first order in osmium concentration, i.e., $b=1$ in eq. 3 . Therefore, the catalytic rate law is:

$$
d\left[\mathrm{H}_{2}\right] / \mathrm{d} t=k[1]
$$

A plot of $d\left[\mathrm{H}_{2}\right] / d t$ versus [1] (Figure 3) provides a value of $1.11 \pm 0.03 \mathrm{~min}^{-1}$ for $k$ at $304 \mathrm{~K}$.

Table 1. Kinetic Data for the Dehydrogenation of Ammonia-Borane Promoted by 1

\begin{tabular}{ccccc}
\hline$T$ & $10^{2}[\mathbf{1}]$ & {$\left[\mathrm{BH}_{3} \mathrm{NH}_{3}\right]$} & $10^{2} d\left[\mathrm{H}_{2}\right] / d t$ & $k$ \\
$(\mathrm{~K})$ & $(\mathrm{M})$ & $(\mathrm{M})$ & $\left.\mathrm{min}^{-1}\right)$ & $\left(\mathrm{min}^{-1}\right)$ \\
\hline 304 & 1.33 & 0.33 & 1.39 & 1.04 \\
304 & 1.67 & 0.33 & 1.90 & 1.14 \\
304 & 2.50 & 0.33 & 2.86 & 1.14 \\
304 & 3.33 & 0.33 & 3.76 & 1.14 \\
304 & 4.20 & 0.33 & 4.59 & 1.09 \\
304 & 1.67 & 0.17 & 2.09 & 1.25 \\
304 & 1.67 & 0.21 & 1.97 & 1.18 \\
304 & 1.67 & 0.25 & 2.06 & 1.23 \\
304 & 1.67 & 0.42 & 1.83 & 1.10 \\
304 & 1.67 & 0.50 & 1.74 & 1.04 \\
293 & 1.67 & 0.33 & 0.51 & 0.31 \\
298 & 1.67 & 0.33 & 1.09 & 0.65 \\
308 & 1.67 & 0.33 & 3.42 & 2.05 \\
313 & 1.67 & 0.33 & 4.62 & 2.77
\end{tabular}

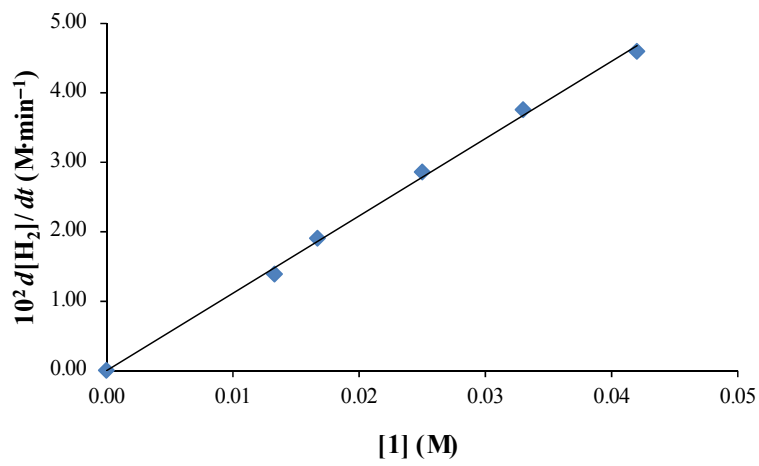

Figure 3. Plot of initial rate of the dehydrogenation of $\mathrm{BH}_{3} \mathrm{NH}_{3}$ $(0.33 \mathrm{M})$ versus $[\mathbf{1}]$ in THF at $304 \mathrm{~K}$.

The lack of dependence on the concentration of ammoniaborane suggests that the unsaturated dihydride 2 , resulting from the dissociation of the olefin from $\mathbf{1}$, rapidly reacts with ammonia-borane to be fully converted to the key intermediate of the catalysis prior to the rate-determining step. In agreement with this, different ${ }^{31} \mathrm{P}\left\{{ }^{1} \mathrm{H}\right\}$ NMR spectra of the catalytic solutions, during the dehydrogenation and at the end of the reaction, show only one singlet at $49.9 \mathrm{ppm}$ (Figure S5) corresponding to the dihydride-dihydrogen derivative $\mathrm{OsH}_{2}\left(\eta^{2}\right.$ $\left.\mathrm{H}_{2}\right)(\mathrm{CO})\left(\mathrm{P}^{\mathrm{i}} \mathrm{Pr}_{3}\right)_{2}(4){ }^{17}$ The activation parameters calculated from the Eyring analysis (Figure 4) are $\Delta H^{*}=19.6 \pm 2.5$ $\mathrm{kcal} \cdot \mathrm{mol}^{-1}$ and $\Delta S^{\ddagger}=6 \pm 9 \mathrm{cal} \cdot \mathrm{mol}^{-1} \cdot \mathrm{K}^{-1}$. The slightly positive value of the activation entropy suggests an increase of the degrees of freedom of the system at the transition state of the 
determining step, which is consistent with a separation of the dihydrogen ligand from the osmium atom and subsequent dissociation to regenerate the dihydride 2 .

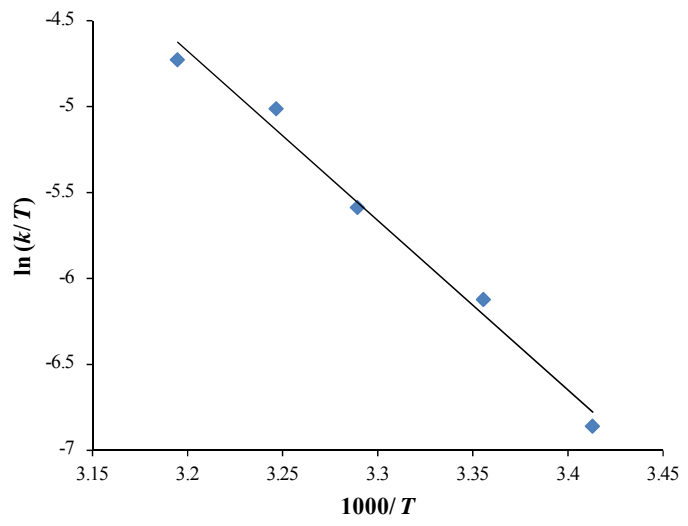

Figure 4. Eyring plot for the dehydrogenation of $\mathrm{BH}_{3} \mathrm{NH}_{3}(0.33$ $\mathrm{M})$ with $\mathbf{1}(1.67 \cdot \mathrm{M})$ in THF.

To gain insight into the formation of the dihydridedihydrogen intermediate $\mathrm{OsH}_{2}\left(\eta^{2}-\mathrm{H}_{2}\right)(\mathrm{CO})\left(\mathrm{P}^{\mathrm{i}} \mathrm{Pr}_{3}\right)_{2}$ (4), we have carried out DFT calculations (M06, 6-31G**/LanL2dz) on the reaction of 2 with ammonia-borane, using $\mathrm{PMe}_{3}$ as phosphine model. The changes in free energy $(\Delta G)$ have been computed in gas phase, at $298.15 \mathrm{~K}$ and $\mathrm{P}=1 \mathrm{~atm}$. Figure 5 shows the energy profile.

Complex $\mathbf{2}$ is an unsaturated square pyramidal cis-dihydride species with one of the hydride ligands $\left(\mathrm{H}^{\mathrm{a}}\right)$ disposed trans to the vacancy. The coordination of ammonia-borane at the latter, in a Shimoi manner, ${ }^{18}$ gives the intermediate $\mathrm{OsH}_{2}\left(\eta^{1}\right.$ $\left.\mathrm{H}_{3} \mathrm{BNH}_{3}\right)(\mathrm{CO})\left(\mathrm{P}^{\mathrm{i}} \mathrm{Pr}_{3}\right)_{2}$ (3) with the coordinated $\mathrm{BH}$-hydrogen situated trans to a hydride $\left(\mathrm{H}^{\mathrm{a}}\right)$ and one of the $\mathrm{NH}$-hydrogens pointing out the other one $\left(\mathrm{H}^{\mathrm{b}}\right)$. The coordination is exothermic by $15.5 \mathrm{kcal} \cdot \mathrm{mol}^{-1}$. Intermediate 3 releases $\mathrm{BH}_{2} \mathrm{NH}_{2}$ after transferring the coordinated HB-hydrogen to the metal center and a NH-hydrogen to the hydride $\mathrm{H}^{\mathrm{b}}$, through a concerted process via TS1, which only lies $14.4 \mathrm{kcal} \cdot \mathrm{mol}^{-1}$ above 3 . This transition state can be described as a $\eta^{1}-\mathrm{H}^{\mathrm{b}}-\mathrm{H}^{\mathrm{N}}$ species where the asymmetric dihydrogen ligand $\left(\mathrm{H}^{\mathrm{b}}-\mathrm{H}^{\mathrm{N}}=0.865 \AA\right)$ is stabilized by interaction with the $\mathrm{NH}_{2}$ group of the boron ligand $\left(\mathrm{H}^{\mathrm{N}}-\mathrm{N}=1.698 \AA\right)$. The hydrogen transfer from ammoniaborane leads to the dihydride-dihydrogen derivative $\mathbf{4 a}$. Its dihydrogen ligand $(\mathrm{H}-\mathrm{H}=0.868 \AA$ ) lies in the perpendicular plane to the $\mathrm{P}-\mathrm{Os}-\mathrm{P}$ direction, between the hydride ligands, trans disposed to the carbonyl group.

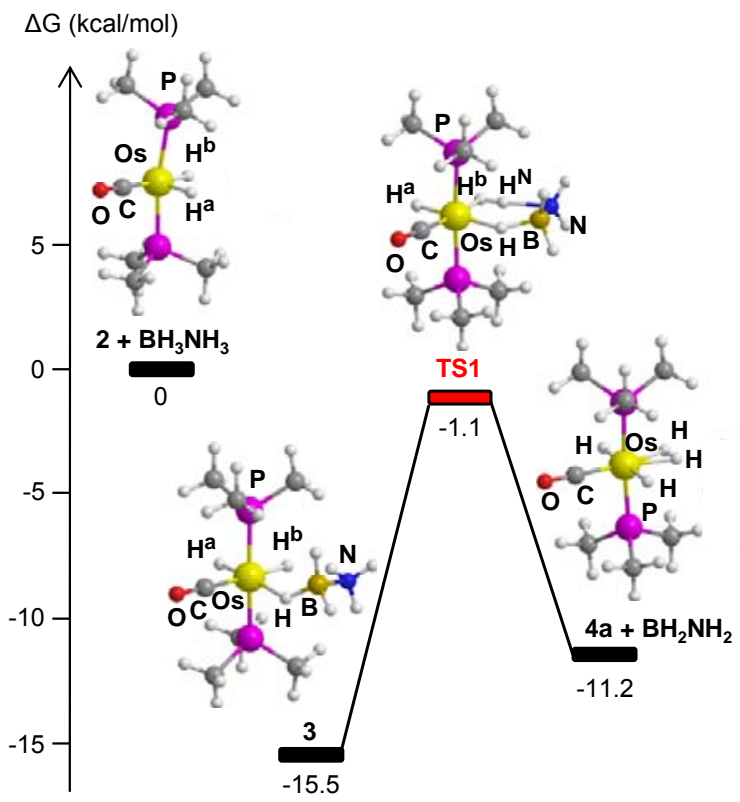

Figure 5. Energy profile ( $\Delta G$ in $\mathrm{kcal} \cdot \mathrm{mol}^{-1}$ ) for $\mathrm{BH}_{3} \mathrm{NH}_{3}$ dehydrogenation, showing the optimized structures of 2, 3, TS1 and 4a. The energy of $\mathbf{2}+\mathbf{B H}_{3} \mathbf{N H}_{3}$ has been taken as reference.

Complex 4a isomerizes via the tetrahydride $\mathbf{4 b}$ into the cisdihydride isomer $\mathbf{4 c}$ (Figure 6). Tetrahydride $\mathbf{4 b}$ is $4.6 \mathrm{kcal}$ $\mathrm{mol}^{-1}$ more stable than $\mathbf{4 a}$ and $1.5 \mathrm{kcal} \mathrm{mol}^{-1}$ less stable than 4c. In the latter, the dihydrogen ligand is disposed almost parallel to the $\mathrm{P}-\mathrm{Os}-\mathrm{P}$ direction. The transformation from $\mathbf{4 a}$ to $4 \mathbf{c}$ occurs through the transition states TS2 and TS3 and is barrierless. In agreement with this, in solution, the hydride and dihydrogen ligands of $\mathrm{OsH}_{2}\left(\eta^{2}-\mathrm{H}_{2}\right)(\mathrm{CO})\left(\mathrm{P}^{\mathrm{i}} \mathrm{Pr}_{3}\right)_{2}$ (4) rapidly exchange their positions, i. e., $4 \mathbf{a}$ and its isomers $\mathbf{4 b}$ and $\mathbf{4 c}$ are living in a fast equilibrium. The coplanar cis disposition of the dihydrogen ligand with regard to both hydrides in $\mathbf{4 a}$ and the protic nature of one of the hydrogen atoms of the dihydrogen ligand ${ }^{19}$ could also facilitate the isomerization without the participation of $\mathbf{4 b}$. The DFT calculated energy for the dissociation of molecular hydrogen from $4 \mathbf{c}$ of $19.4 \mathrm{kcal} \mathrm{mol}^{-1}$ agrees well with that obtained from Figure 4. Caulton and coworkers have estimated by ${ }^{1} \mathrm{H}$ NMR spectroscopy a $\Delta G^{\ddagger}$ (95 $\left.{ }^{\circ} \mathrm{C}\right)$ value of $19.6 \pm 0.5 \mathrm{kcal} \cdot \mathrm{mol}^{-1}$ for the dihydrogen dissociation from the equilibrium mixture, ${ }^{20}$ which is also in agreement with that calculated from the Eyring plot $(17.3 \pm 3$ $\mathrm{kcal} \cdot \mathrm{mol}^{-1}$ ).

The cycle shown in Scheme $2,{ }^{21}$ which is consistent with the kinetic results, introduces the results of the DFT calculations in the catalytic context. The ${ }^{11} \mathrm{~B}\left\{{ }^{1} \mathrm{H}\right\}$ NMR spectra of the catalytic solutions do not contain any different signal as that of ammonia-borane, neither the spectra at the end of the reaction. This along with the rate law shown in eq 4 suggest that the aminoborane polymerization is an off-metal process ${ }^{22}$ of low activation energy, which probably occurs by nucleophilic solvent assistance. 


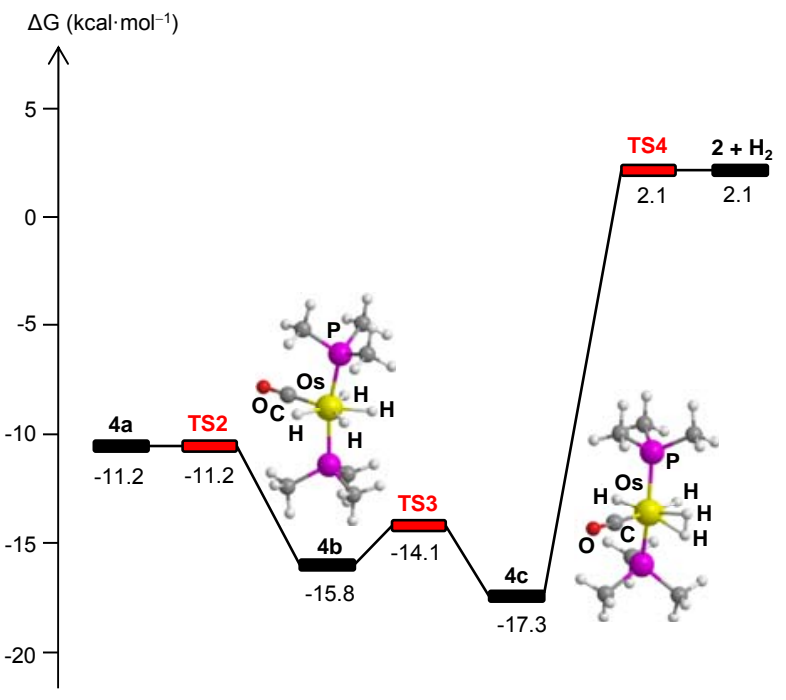

Figure 6. Energy profile ( $\Delta G$ in $\left.\mathrm{kcal} \cdot \mathrm{mol}^{-1}\right)$ for the hydride/dihydrogen site exchange in $\mathbf{4}$ and $\mathrm{H}_{2}$ dissociation, showing the optimized structures of intermediates $\mathbf{4 b}$ and $\mathbf{4 c}$. The Gibbs energy of $\mathrm{BH}_{2} \mathrm{NH}_{2}$ was added to compare with Gibbs energy values of Figure 5 (see the Supporting Information).

Scheme 2. Catalytic Cycle for the $\mathrm{BH}_{3} \mathrm{NH}_{3}$ Dehydrogenation Promoted by 1.

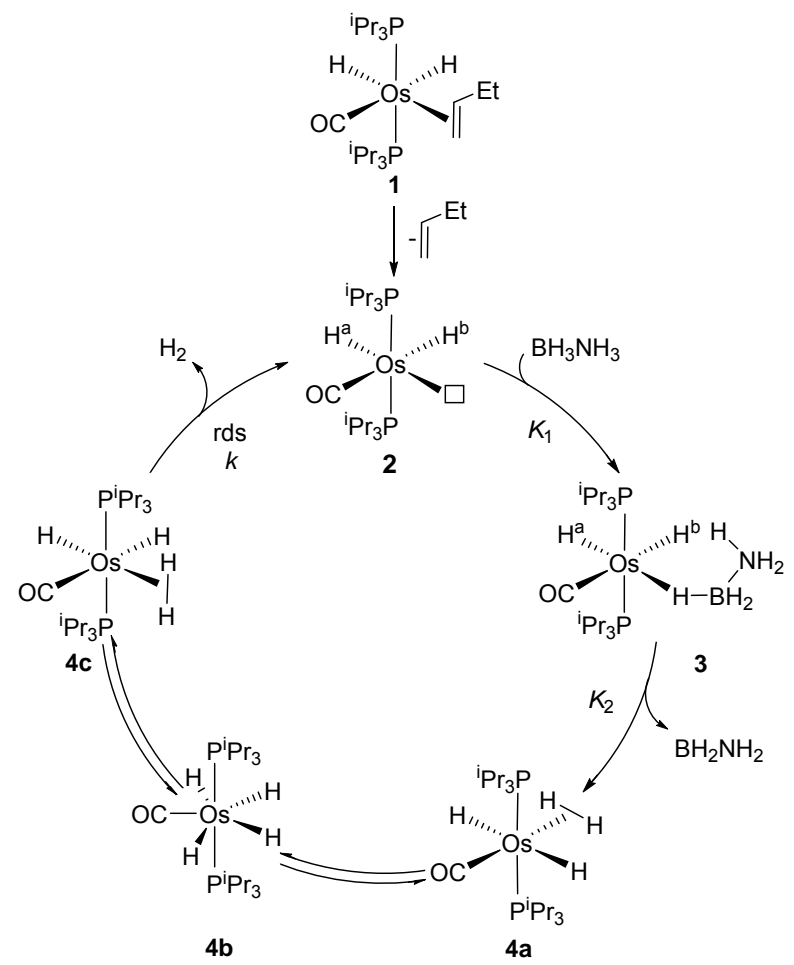

In conclusion, the unsaturated dihydride $\mathrm{OsH}_{2}(\mathrm{CO})\left(\mathrm{P}^{\mathrm{i}} \mathrm{Pr}_{3}\right)_{2}$ promotes the release of 1 equiv of $\mathrm{H}_{2}$ from ammonia-borane. The dehydrogenation take place via the dihydride-dihydrogen complex $\mathrm{OsH}_{2}\left(\eta^{2}-\mathrm{H}_{2}\right)(\mathrm{CO})\left(\mathrm{P}^{\mathrm{i}} \mathrm{Pr}_{3}\right)_{2}$, which is formed by concerted $\mathrm{BH}$ - and $\mathrm{NH}$-hydrogen transfers from the amine-borane to the metal center and to a hydride ligand, respectively, without any change in the metal oxidation state nor ligand assistance.

\section{ASSOCIATED CONTENT}

Supporting Information. Experimental details, characterization data, and computational details. This material is available free of charge via the Internet at http://pubs.acs.org.

\section{AUTHOR INFORMATION}

\section{Corresponding Author}

E-mail: maester@unizar.es.

\section{Author Contributions}

The manuscript was written through contributions of all authors. / All authors have given approval to the final version of the manuscript. /

\section{ACKNOWLEDGMENT}

Financial support from the Spanish MINECO (Projects CTQ201123459 and Consolider Ingenio 2010 (CSD2007-00006)), the DGA (E35), and the European Social Fund (FSE) is acknowledged. M.M. thanks the Spanish MEC for her FPU grant.

\section{REFERENCES}

(1) (a) Yadav, M.; Xu, Q. Energy Environ. Sci. 2012, 5, 96989725. (b) Dalebrook, A. F.; Gan, W.; Grasemann, M.; Moret, S.; Laurenczy, G. Chem. Commun. 2013, 49, 8735-8751.

(2) See for example: (a) Clark, T. J.; Lee, K.; Manners, I. Chem. Eur. J. 2006, 12, 8634-8648. (b) Stephens, F. H.; Pons, V.; Baker, R. T. Dalton. Trans. 2007, 2613-2626. (c) Hamilton, C. W.; Baker, R. T.; Staubitz, A.; Manners, I. Chem. Soc. Rev. 2009, 38, 279-293. (d) Staubitz, A.; Robertson, A. P. M.; Sloan, M. E.; Manners, I. Chem. Rev. 2010, 110, 4023-4078. (e) Staubitz, A.; Robertson, A. P. M.; Manners, I. Chem. Rev. 2010, 110, 4079-4124.

(3) See for example: García-Vivó, D.; Huergo, E.; Ruiz, M. A.; Travieso-Puente, R. Eur. J. Inorg. Chem. 2013, 4998-5008.

(4) (a) Vance, J. R.; Robertson, A. P. M.; Lee, K.; Manners, I. Chem. Eur. J. 2011, 17, 4099-4103. (b) Baker, R. T.; Gordon, J. C.; Hamilton, C. W.; Henson, N. J.; Lin, P.-H.; Maguire, S.; Murugesu, M.; Scott, B. L.; Smythe, N. C. J. Am. Chem. Soc. 2012, 134, 55985609. (c) Sonnenberg, J. F.; Morris, R. H. ACS. Catal. 2013, 3, 1092 1102. (d) Bhattacharya, P.; Krause, J. A.; Guan, H. J. Am. Chem. Soc. 2014, 136, 11153-11161.

(5) (a) Blaquiere, N.; Diallo-Garcia, S.; Gorelsky, S. I.; Black, D. A.; Fagnou, K. J. Am. Chem. Soc. 2008, 130, 14034-14035. (b) Kä $\beta$, M.; Friedrich, A.; Drees, M.; Schneider, S. Angew. Chem. Int. Ed. 2009, 48, 905-907. (c) Conley, B. L.; Williams, T. J. Chem. Commun. 2010, 46, 4815-4817. (d) Conley, B. L.; Guess, D.; Williams, T. J. J. Am. Chem. Soc. 2011, 133, 14212-14215. (e) Schreiber, D. F.; O'Connor, C.; Grave, C.; Ortin, Y.; Müller-Bunz, H.; Phillips, A. D. ACS Catal. 2012, 2, 2505-2511. (f) Marziale, A. N.; Friedrich, A.; Klopsch, I.; Drees, M.; Celinski, V. R.; auf der Günne, J. S.; Schneider, S. J. Am. Chem. Soc. 2013, 135, 13342-13355.

(6) See for example: (a) Jaska, C. A.; Temple, K.; Lough, A. J.; Manners, I. Chem. Commun. 2001, 962-963. (b) Jaska, C. A.; Temple, K.; Lough, A. J.; Manners, I. J. Am. Chem. Soc. 2003, 125, 9424 9434.

(7) (a) Denney, M. C.; Pons, V.; Hebden, T. J.; Heinekey, D. M. Goldberg, K. I. J. Am. Chem. Soc. 2006, 128, 12048-12049. (b) John, A. S.; Goldberg, K. I.; Heinekey, D. M. Top Organomet. Chem. 2013, 40, 271-288

(8) (a) Keaton, R. J.; Blacquiere, J. M.; Baker, R. T. J. Am. Chem. Soc. 2007, 129, 1844-1845. (b) Yang, X.; Hall, M. B. J. Am. Chem. Soc. 2008, 130, 1798-1799.

(9) Kim, S.-K.; Han, W.-S.; Kim, T.-J.; Kim, T.-Y.; Nam, S. W Mitoraj, M.; Piekoś, L.; Michalak, A.; Hwang, S.-J.; Kang, S. O. J. Am. Chem. Soc. 2010, 132, 9954-9955.

(10) Primary and secondary amine-boranes are also efficiently dehydrogenated by transition metal compounds. For some relevant papers, see: (a) Pun, D.; Lobkovsky, E.; Chirik, P. J. Chem. Commun. 
2007, 3297-3299. (b) Sloan, M. E.; Staubitz, A.; Clark, T. J.; Russell, C. A.; Lloyd-Jones, G. C.; Manners, I. J. Am. Chem. Soc. 2010, 132, 3831-3841. (c) Vogt, M.; de Bruin, B.; Berke, H.; Trincado, M.; Grützmacher, H. Chem. Sci. 2011, 2, 723-727. (d) Dallanegra, R.; Robertson, A. P. M.; Chaplin, A. B.; Manners, I.; Weller, A. S. Chem. Commun. 2011, 47, 3763-3765. (e) Sewell, L. J.; Lloyd-Jones, G. C.; Weller, A. S. J. Am. Chem. Soc. 2012, 134, 3598-3610. (f) RosellóMerino, M.; López-Serrano, J.; Conejero, S. J. Am. Chem. Soc. 2013, 135, 10910-10913. (g) Johnson, H. C.; Leitao, E. M.; Whittell, G. R.; Manners, I.; Lloyd-Jones, G. C.; Weller, A. S. J. Am. Chem. Soc. 2014, 136, 9078-9093. (h) Vance, J. R.; Schäfer, A.; Robertson, A. P. M.; Lee, K.; Turner, J.; Whittell, G. R.; Manners, I. J. Am. Chem. Soc. 2014, 136, 3048-3064.

(11) Waterman, R. Chem. Soc. Rev. 2013, 42, 5629-5641.

(12) Paul, A.; Musgrave, C. B. Angew. Chem. Int. Ed. 2007, 46, 8153-8156.

(13) Esteruelas, M. A.; Fernández, I.; López, A. M.; Mora, M.; Oñate, E. Organometallics. 2014, 33, 1104-1107.

(14) (a) Esteruelas, M. A.; Werner, H. J. Organomet. Chem. 1986, 303, 221-231. (b) Esteruelas, M. A.; Oro, L. A. Adv. Organomet. Chem. 2001, 47, 1-59.

(15) (a) Albéniz, M. J.; Buil, M. L.; Esteruelas, M. A.; López, A. M.; Oro, L. A.; Zeier, B. Organometallics 1994, 13, 3746-3748. (b) Albéniz, M. J.; Buil, M. L.; Esteruelas, M. A.; López, A. M. Organomet. Chem. 1997, 545-546, 495-506.

(16) As can be seen in Figure S1, the IR spectrum of the insoluble white material obtained is identical to that reported by Manners et al. (see: Staubitz, A.; Soto, A. P.; Manners, I. Angew. Chem. Int. Ed. 2008, 47, 6212-6215). Recently, this solid has been further characterized as a polymer by ultrahigh resolution electrospray mass spectrometry (ESI-MS), ${ }^{11} \mathrm{~B}$ and ${ }^{1} \mathrm{H}$ solid-state NMR, and wideangle Xray scattering (WAXS) (see: Staubitz, A.; Sloan, M. E.; Robertson, A.

P. M.; Friedrich, A.; Schneider, S.; Gates, P. J.; Schmedt auf der Günne, J.; Manners, I. J. Am. Chem. Soc. 2010, 132, 13332-13345).

(17) Werner, H.; Esteruelas, M. A.; Meyer, U.; Wrackmeyer, B. Chem. Ber. 1987, 120, 11-15.

(18) Kawano, Y.; Yamaguchi, K.; Miyake, S.; Kakizawa, T.; Shimoi, M. Chem. Eur. J. 2007, 13, 6920-6931.

(19) (a) Esteruelas, M. A.; Oro, L. A. Chem. Rev. 1998, 98, 577588. (b) Kubas, K. Chem. Rev. 2007, 107, 4152-4205.

(20) Gusev, D. G.; Kuhlman, R. L.; Renkema, K. B.; Eisenstein, O.; Caulton, K. G. Inorg. Chem. 1996, 35, 6775-6783.

(21) This cycle is strongly supported by the rate law show in eq 4. According to the rate determining step approximation $\mathrm{d}\left[\mathrm{H}_{2}\right] / \mathrm{d} t=k[4]$, where $[4]=[1]-[2]-[3] . \quad$ However $[2]=[4] \cdot\left[\mathrm{H}_{2} \mathrm{~B}=\mathrm{NH}_{2}\right] / K_{1} \cdot K_{2} \cdot\left[\mathrm{BH}_{3} \mathrm{NH}_{3}\right] \approx 0 \quad$ and $[3]=[4] \cdot\left[\mathrm{H}_{2} \mathrm{~B}=\mathrm{NH}_{2}\right] / K_{2} \approx 0$ because the species $\mathrm{H}_{2} \mathrm{~B}=\mathrm{NH}_{2}$ polymerizes. Thus, $[4]=[\mathbf{1}]$ and $\mathrm{d}\left[\mathrm{H}_{2}\right] / \mathrm{d} t=k[\mathbf{1}]$.

(22) An on-metal polymerization process should involve that $[\mathbf{1}]=$ [4] $+[5]$, being 5 the metal species responsible of the polymerization, and therefore the rate law of eq 4 should not be possible.

(23) Malakar, T.; Roy, L.; Paul, A. Chem. Eur. J. 2013, 19, 58125817. 
TOC

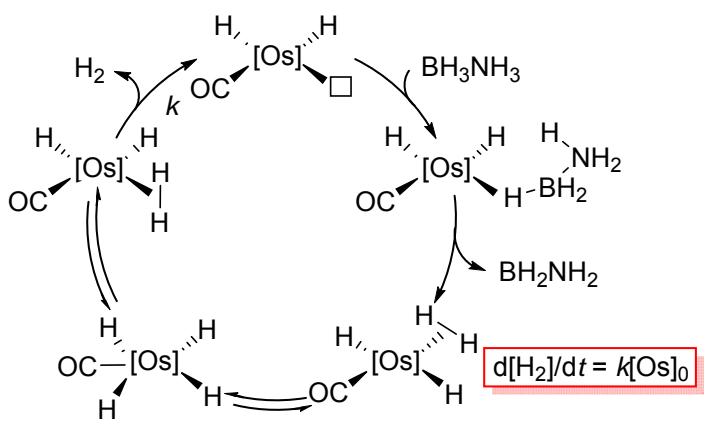

$[\mathrm{Os}]=\mathrm{Os}\left(\mathrm{PiPr}_{3}\right)_{2}$ 